\title{
Light Up the "No-man's Land" on the Brain Stem
}

\author{
Takeshi Kawase \\ Department of Neurosurgery, School of Medicine, Keio University, Tokyo, Japan
}

(Received for publication on September 11, 1995)

\begin{abstract}
The ventral surface of the brain stem is anatomically surrounded by the clivus anteriorly, brain stem posteriorly and by the petrous pyramid and cranial nerves from IIIrd to XIIth laterally in the deep posterior cranial fossa. Neurosurgical extra-axial pathologies arising from the area are aneurysms on the vertebro-basilar artery, benign tumors such as clival meningiomas, chordomas, chondromas, trigeminal neurinomas and prepontine epidermoid tumors. Surgical access to the area had been difficult for long years since the neurosurgery was established, because located deeply in such a surgical blindness, so-called "no-man's land". However, recent technical development of "skull base surgery" is opening new doors to light up the surgical darkness of the "no-man's land. This paper reviews the history, development. technique and future prospect of the skull base surgery to open the "no-man's land". (Keio I Med 44 (4): 133-139, December 1995)
\end{abstract}

Key words: skull base, posterior cranial fossa, clivus, surgical technique

\section{Historical Background}

The first surgical access was made to the posterior fossa aneurysms via the suboccipital route by Dandy ${ }^{1}$ in 1944. Neurosurgical pioneers ${ }^{2-4}$ performed the similar trial to the aneurysms in the early neurosurgical decades, however the surgical results were not acceptable because of damage to the cranial nerves and brain stem, with distressing morbidity and mortality. In 1965, Drake ${ }^{5}$ reported better surgical results to the basilar bifurcation aneurysms via the subtemporal route, and established successful surgical method and results by his approach and by the development of surgical microscope in the late '60th. The upper basilar aneurysms were already in the illuminated in the surgical field, however, aneurysms on the lower basilar trunk located behind the clivus were still in the darkness of the "no-man's land".

Surgical exploration of the clival meningioma was made by Olivecrona in 1927, but it had been concluded for long years that they were inoperable after his unacceptable experience of 8 cases. ${ }^{6}$ The suboccipital route was used for cerebellopontine angle tumors, ${ }^{7.8}$ but did not offer enough space between the cranial nerves and the brain stem for the clival tumors. Surgical injury to the lower cranial nerves resulted serious postsurgical complications such as dysphagia and pneumonia. The subtemporal-transtentorial approach was developed by Bonnal et al in $1964,{ }^{4}$ and offered wider surgical field to the clivus. However, the disadvantage was the risk of retraction damage on the temporal lobe, leading aphasia, hemiparesis or epilepsy. ${ }^{10.11}$ An additional problem of meningiomas was epidural extension towards the petrous apex and the cavernous sinus. Yasargil experienced 19 surgical cases of clival meningiomas by variable surgical approaches, and stated in $1980^{10}$ that none of his used approaches was entirely satisfactory. Thus tumor might partially be left behind cranial nerves, on the deep clivus and in the cavernous sinus in the difficult case.

An another surgical approach to the clivus was transnasal or transoral approach. Laws ${ }^{12}$ indicated the transnasal-transsphenoidal approach, which has commonly been applied for pituitary adenomas since Hardy ${ }^{13}$ popularized the technique. The approach allowed visualization of upper third of the clivus, but with limited space for extensive lesions. The transoral route had a long history since Kanaval ${ }^{14}$ performed in 1919 for basal trauma, and has been applied mainly for pathology ventral to the upper cervical spine and foramen magnum. ${ }^{15-18}$ The

Reprint requests to: Dr Takeshi Kawase, Department of Neurosurgery, School of Medicinc, Keio University, 35 Shinanomachi, Shinjuku-ku, Tokyo 160, Japan 
transoral approach was gradually extended its indication to the lower clival lesions such as chordomas ${ }^{17}$ by split the soft palate. It was applied to the midline located vertebro-basilar aneurysms by Sano in $1966^{19}$ and by Fox in 1967. ${ }^{21}$ However disadvantages of this approach were limited surgical field and difficulty of dural closure leading to postoperative cerebrospinal leakage with risk of meningitis. Drake ${ }^{21}$ and Yasargil ${ }^{10}$ criticized the transoral approach to the subdural lesions as "high risk surgery". However, it had an advantage to the epidural pathologies.

Development of the skull base surgery was supported by multiple fields; department of otolaryngology, plastic surgery, ophthalmology, neuroradiology as well as neurosurgery, and by the development of medical instruments, materials and electronics. The surgical technology was advanced for temporal bone tumors by pioneers in otolaryngology, and head and neck surgery ${ }^{22-2 t}$ in the '70th. Development of craniofacial surgery in the field of plastic surgery enlarge the possibility of surgical access and postoperative reconstruction. In 1980th, the skull base surgery was illuminated as a new surgical field where neurosurgerons challenge to operate the pathologies difficult to be treated by conventional surgical techniques. The surgical approaches to the "no-man's land" were categorized into following three groups; middle fossa transpetrosal approach, lateral suboccipital approach and transoral approach.

\section{Surgical Approaches to the "No-man's Land"}

Middle fossa transpetrosal approaches (Extended middle fossa approach)

Surgical removal of the pyramidal bone has been used mainly for cerebellopontine angle (CPA) tumors since $1970 .{ }^{25-30}$ This approach is a combination of the subtemporal and translabyrinthine approaches, and gives the surgeon the possibility of reaching the CPA and midfrontal portion of the pons from the drilled pyramidal bone. In 1977, the transpetrosal approach was applied to the clival meningioma. ${ }^{31}$ Advantages of the approach were wider surgical exposure and minimal brain damage because accessed epidurally from the space of the resected pyramidal bone to spare brain retraction and sacrifice of the bridging veins. A high tumor radicality was achieved in meningiomas removed with attached dura. Disadvantages were sacrificed hearing and risk of cerebrospinal fluid rhinorrhea. In 1985, limited pyramidal resection antero-medial to the auditory organs (anterior transpetrosal approach) was reported for preservation of hearing in clipping of aneurysms of the lower basilar artery. ${ }^{32}$ An another advantage of the anterior approach was easy access to the parasellar area from a small middle fossa craniotomy, being indicated to the petroclival meningiomas with parasellar invasion. ${ }^{33.34}$ Thus the transpetrosal approach, even modified by surgeons, ${ }^{35-38}$ became an relevant surgical approach to the upper clivus and brain stem, upper half of the no-man's land (Table 1).

Surgical technique of the middle fossa transpetrosal approach: 1) Transpetrosal approach with preserved hearing: The approach is indicated for patients with preoperative useful hearing. The skin incision and craniotomy site are made on the temporal area, slightly varied from the site of pyramid resection. After dissection of the dura on the temporal pyramid, the pyramidal bone is drilled off extradurally. Hearing can be preserved if the bone resection is limited anterior or posterior to the organic bone, such as cochlea and labyrinth. The anterior spot is surrounded by the trigeminal impression anteriorly, the eminentia arcuata posteriorly, the major petrosal groove and cochlea laterally, and the carotid canal and internal auditory canal inferiorly. Detachment of the middle meningeal artery is necessary to expose the area. The approach is named anterior transpetrosal approach (Fig 1A), ${ }^{33}$ and upper half of the clivus and basilar trunk are accessible between the 3rd and 7 th cranial nerves. The posterior spot is surrounded by the semicircular canal of the labyrinth anteriorly, the sigmoid sinus

Table 1 Variation of Transpetrosal Approaches

\begin{tabular}{|c|c|c|c|}
\hline Name of Surgery & Advantages & Disadvantages & Indication \\
\hline Anterior TPA & $\begin{array}{l}\text { hearing prescrved } \\
\text { parasellar overview }\end{array}$ & limited space & $\begin{array}{l}\text { upper clival tumors. } \\
\text { BA trunk aneurysm }\end{array}$ \\
\hline Presigmoid TPA & hearing preserved & $\begin{array}{l}\text { venous complication, } \\
\text { limited space }\end{array}$ & $\begin{array}{l}\text { mid-clival and jugular } \\
\text { tumors, VBJ aneurysm }\end{array}$ \\
\hline Posterior TPA & IAM overvicw & hearing sacrificed & CPA tumors \\
\hline Total Petrosectomy & $\begin{array}{l}\text { wide overvicw to } \\
2 / 3 \text { clivus and CPA }\end{array}$ & $\begin{array}{l}\text { long operation, } \\
\text { hearing sacrificed }\end{array}$ & large petroclival tumors \\
\hline
\end{tabular}

TPA; transpetrosal approach, BA; basilar artery, VBJ; vertebrobasilar junction, CPA; cerebello-pontine angle, IAM; internal auditory meatus. 
posteriorly and the jugular bulb inferiorly (Trautman's triangle). The disadvantage was risk of venous complication, because the sigmoid sinus must be mobilized posteriorly. The approach is named presigmoid transpetrosal approach (Fig 1B), ${ }^{31}$ and the middle clivus and

A

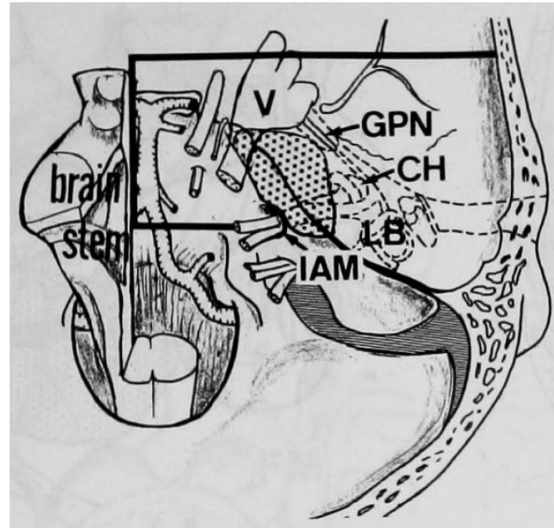

B

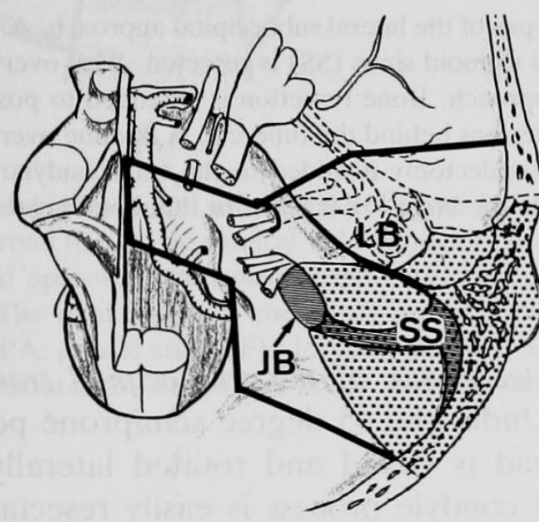

C

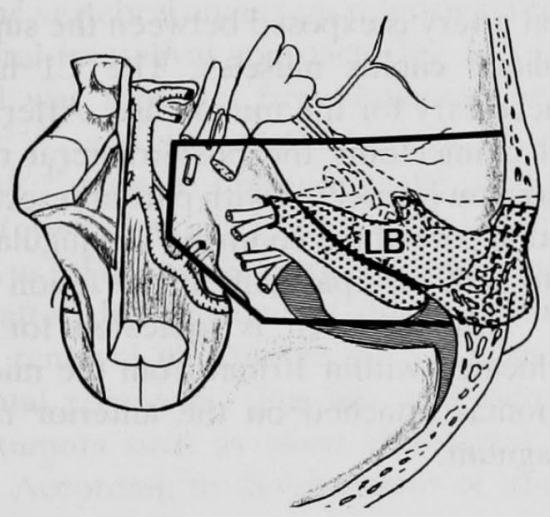

D

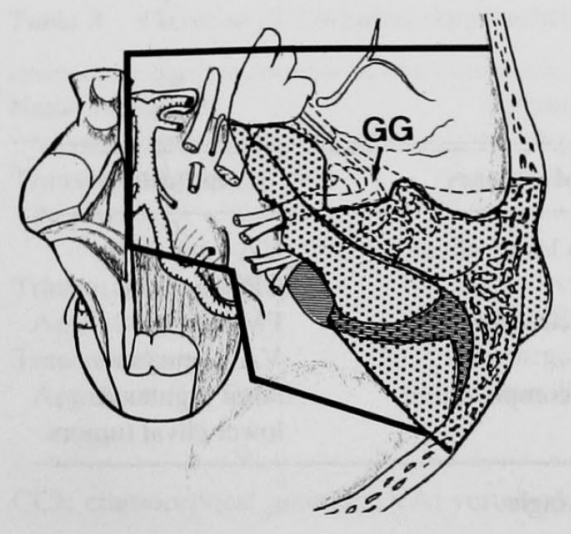

vertebro-basilar union are accessible between the 8th and 9th cranial nerves. Complete incision of the tentorium with detachment of the petrosal sinus enlarge the surgical field of either approach. Cerebrospinal fluid rhinorrhea is prevented by covering the pyramid with a grafted temporal fascia and fibrin glue.

2) Transpetrosal approach with sacrificed hearing: The approach is indicated for patients without preoperative useful hearing, or for whom hearing preservation is not anticipated. A horseshoe scalp incision and craniotomy are made above the external auditory meatus, slightly posterior to the anterior transpetrosal approach. The mastoid air cells are resected partially, and the posterior petrous pyramid including labyrinth, is resected until the internal auditory meatus is opened (posterior transpetrosal approach) (Fig 1C). The tentorium is incised above the meatus. Total resection of the pyramid including the anterior part (total petrosectomy) offers a wide surgical field from IIIrd to XIth cranial nerves, and indicated large petroclival tumors extending posteriorly to the internal auditory meatus (Fig 1D). The cerebrospinal fluid leakage is prevented with a free muscle piece plunged in the tympanic cavity, and a temporal fascia or abdominal fat tissues covered on the pyramidal air cells.

\section{Lateral suboccipital approaches}

Lesions on the lower clivus or on the anterior rim of the foramen magnum were still in the lower "noman's land". The pertinent pathologies were vertebral aneurysms and foramen magnum meningiomas which located within $1 \mathrm{~cm}$ from the midline. They are laid in the bone groove surrounded by the condylar process and

Fig 1 Site of bone resection (dotted) and limit of the surgical field (broad line) in various types of the transpetrosal approach (TPA). A: Anterior TPA. The bone resection is limited in the inorganic apical petrous pyramid. This approach covers the upper clivus and parasellar region under preserved hearing. IAM; internal auditory meatus, V; trigeminal nerve, GPN; greater petrosal nerve, LB; labyrinth, CH; cochlea B: Presigmoid TPA. The temporo-occipital bone, posterior to the labyrinth (LB) is resected with the mastoid process. By posterior mobilization of the sigmoid sinus (SS), the surgical field is opened to the mid-clivus, under preserved hearing. JB; jugular bulb. C: Posterior TPA. The bone resection is in the area posterior to the internal auditory meatus (IAM), including the upper mastoid and labyrinth (LB). Indicated for patients with lost hearing in cerebellopontine angle tumors. $\mathrm{D}$ : Total petrosectomy. The pyramidal bone is totally resected except for that on the geniculate ganglion of the facial nerve (GG). A wide surgical field is obtainable except for area of foramen magnum. 


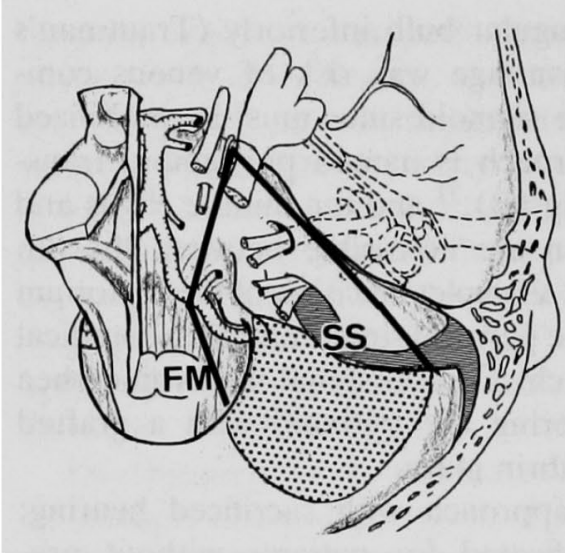

A

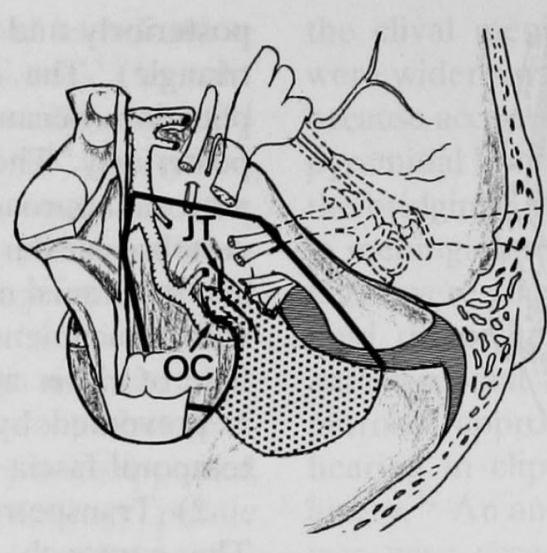

B

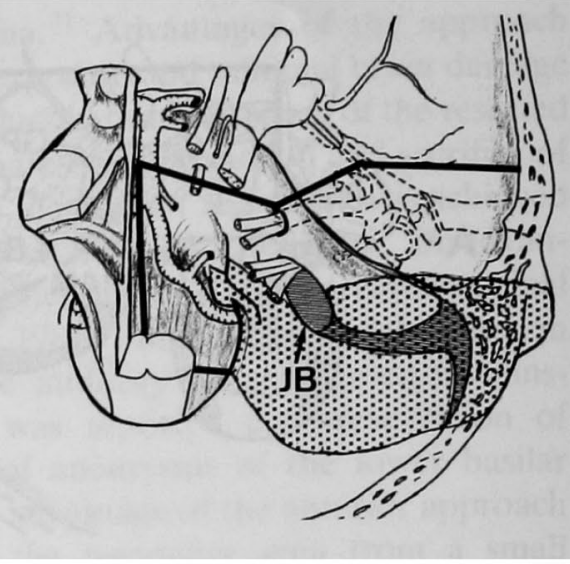

C

Fig 2 Site of bone resection (dotted) and limit of surgical field (broad line) in various types of the lateral suboccipital approach. A: Far lateral suboccipital approach. Occipital bone bridge between the foramen magnum (FM) and sigmoid sinus (SS) is resected. Well overview to the cerebellopontine angle but limitation to the midline. B: Suboccipital transcondylar approach. Bone resection is extended to posteromedial part of the occipital condyle (OC). The jugular tubercle (JT) is optionally resected for lesions behind the tubercle. A midline overview to the lower clivus and foramen magnum. C: Extreme lateral transcondylar approach. Mastoidectomy is added to the transcondylar approach. Jugular bulb (JB) is exposed and the sigmoid sinus is mobilized anteriorly. Indicated to the large lower clival or dumbbell jugular tumors.

jugular tubercle. The medulla oblongata, located posteriorly, is immobilized by the lower cranial nerves. The opening key is to access laterally as possible by resection of the lateral rim of the foramen magnum from the suboccipital craniectomy (far lateral suboccipital approach (Fig 2A). ${ }^{39-41}$ ) Bertalanffy ${ }^{42}$ reported "transcondylar approach" (Fig 2B) by partial resection of the occipital condyle without problem of neck instability, and indicated to the midline-located vertebral aneurysms and to the small or medium sized tumors. This approach may be beneficial to the vertebro-basilar union aneurysms as well, if the jugular tubercle can be resected. ${ }^{40,43}$ The disadvantage may be the risk of laceration of veins around the jugular bulb. $\operatorname{Sen}^{44}$ described further bone resection including mastoidectomy and transposition of the vertebral artery, named "extreme lateral approach" (Fig 2C), and indicated to large lower clival or jugular tumors (Table 2).
Surgical technique of the suboccipital transcondylar approach: Under the 45 degree semiprone position the patient's head is flexed and rotated laterally. By this position the condyle process is easily resectable, being positioned at the most posterior part of the joint. A curved incision is made behind the mastoid process and the vertebral artery is exposed between the superior and inferior oblique capitis muscles. The $\mathrm{C} 1$ hemilaminectomy is necessary for the tumor case. After unilateral suboccipital craniectomy the posterolateral rim of the foramen magnum is resected with partial resection of the postero-medial part of the condyle. The jugular tubercle is capable to drill off epidurally if the lesion is located behind. ${ }^{42,43}$ This approach is indicated for vertebral aneurysms located within $10 \mathrm{~mm}$ from the midline, and for meningiomas attached on the anterior rim of the foramen magnum.

Table 2 Variation of Lateral Suboccipital Approaches

\begin{tabular}{|c|c|c|c|}
\hline Name of Surgery & Advantages & Disadvantages & Indication \\
\hline $\begin{array}{l}\text { Far Lateral } \\
\text { Suboccipital Approach }\end{array}$ & simple technique & blind to lower clivus & $\begin{array}{l}\text { VA aneurysm, } \\
\text { CPA tumors }\end{array}$ \\
\hline $\begin{array}{l}\text { Suboccipital } \\
\text { Transcondylar Approach } \\
\text { Extreme lateral } \\
\text { Transcondylar Approach }\end{array}$ & $\begin{array}{l}\text { overview to anterior } \\
\text { FM \& lower clivus } \\
\text { wide surgical field }\end{array}$ & $\begin{array}{l}\text { venous complication } \\
\text { venous complication }\end{array}$ & $\begin{array}{l}\text { FM tumors, } \\
\text { VA aneurysm } \\
\text { large jugular \& } \\
\text { lower clival tumors }\end{array}$ \\
\hline
\end{tabular}

VA; vertebral artery, FM; foramen magnum, CPA; cerebello-pontine angle. 


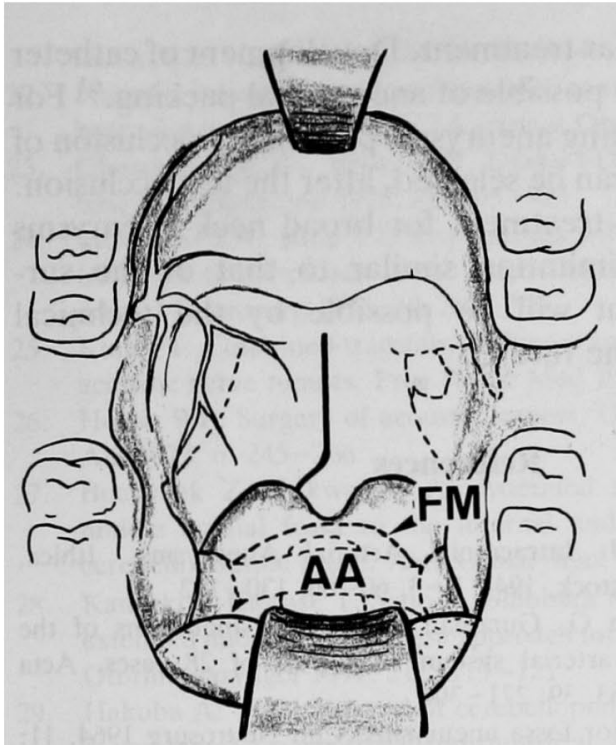

A

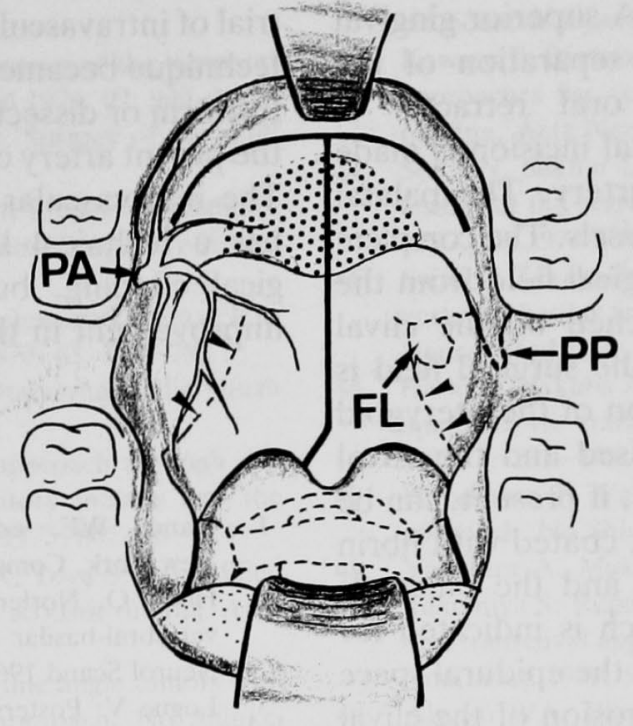

B

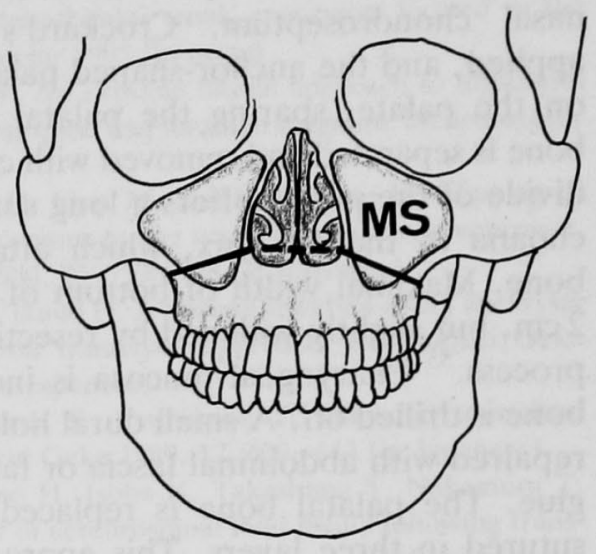

Fig 3 Site of incision and osteotomy in various types of transoral approach. A: Transoral-transclival approach. The soft palate is optionally divided (broad line). The surgical field is limited around the craniocervical junction. FM; foramen magnum, AA; atlas arch.B: Transoraltranspalatal approach (cleft palatal approach). An anchor shaped palatal incision (broad line) is followed by removal of the palatal bone (dotted). The total length of the clivus can be exposed. Medial pterygoid process (PP) is optionally resected subcutaneously for lateral overview. PA; palatal artery, FL; foramen lacerum, arrowheads; lateral margin of the clivus. C: Transmaxillar approach (Le-Fort I). A broad line demonstrates the site of osteotomy. Maxillar sinuses (MS) are opened.

\section{Transoral approaches}

Since the vertebral aneurysm was originally clipped by the transoral-transclival approach (Fig 3A) in '60th, the same trial was reported from Japanese neurosurgeon in ' 80 th, ${ }^{45-47}$ and the method of dural closure was described. ${ }^{47,48}$ However bottom of the surgical field was still small (approximately 1 square $\mathrm{cm}$ ) and limited in the lower clivus. The upper surgical field was markedly enlarged after development of divide of soft palate, ${ }^{49}$ and after removal of hard palate. ${ }^{50}$ Those are named "transpalatal approach" (Fig 3B), and indicated to the epidural tumors such as clival chordomas and angiofibromas. According to development of fibrin glue the dural closure became easier, and it was indicated to the intradural lesions located in the midline, such as small meningiomas, neurinomas, or aneurysms. ${ }^{51}$ In 1989, the transoral approach was combined with the Le Fort I maxillotomy (Fig 3C), applied to the clival tumors and vertebrobasilar aneurysms, ${ }^{52,53}$ and extended the lateral surgical field. The transmaxillar or transfacial approach, ${ }^{54}$ however, was used mainly for malignant tumors, and the evaluation has not been widely accepted for benign lesions, because of the high surgical intervention (Table 3).

Surgical technique of the transoral-transpalatal approach: Under the supine position the patient's jaw is

Table 3 Variation of Transoral Approaches

\begin{tabular}{llll}
\hline \hline Name of Surgery & Advantages & Disadvantages & Indication \\
\hline $\begin{array}{l}\text { Transoral-transclival } \\
\text { Approach }\end{array}$ & $\begin{array}{l}\text { no retraction of } \\
\text { brain stem }\end{array}$ & $\begin{array}{l}\text { limited space, } \\
\text { neck fixation, } \\
\text { dural closure* } \\
\text { limited lateral view } \\
\text { dural closure* } \\
\text { dental complication } \\
\text { dural closure* }\end{array}$ & $\begin{array}{l}\text { CCJ pathologies, } \\
\text { midline VA aneurysm }\end{array}$ \\
$\begin{array}{ll}\text { Approach } \\
\text { Transmaxillary }\end{array}$ & $\begin{array}{l}\text { long overview } \\
\text { along midline } \\
\text { Approach (Le-Fort I) }\end{array}$ & $\begin{array}{l}\text { clival chordoma } \\
\text { with midline extension } \\
\text { malignant tumors, } \\
\text { incl. maxillar sinus }\end{array}$ & $\begin{array}{l}\text { clival chordoma with } \\
\text { lateral extension }\end{array}$ \\
\hline
\end{tabular}

CCJ; craniocervical junction, VA; vertebral artery, * in case of subdural pathologies. 
lifted with a pad under his shoulder. A superior gingival incision is followed by submucosal separation of the nasal chondroseptum. Crockard's oral retractor is applied, and the anchor-shaped palatal incision is made on the palate, sparing the palatal artery. The palatal bone is separated and removed with chisels. The complete divide of the palate offers a long surgical field from the choana to the pharynx, which attached on the clival bone. Maximal width of bottom of the surgical field is $2 \mathrm{~cm}$, but slightly widened by resection of the pterygoid process. ${ }^{55}$ Pharyngeal mucosa is incised and the clival bone is drilled off. A small dural hole, if present, can be repaired with abdominal fascia or fat, coated with fibrin glue. The palatal bone is replaced, and the palate is sutured in three layers. This approach is indicated for clival chordomas, extending mainly in the epidural space below the pharyngeal mucosa with erosion of the clival bone. This approach is still controversial for clipping of vertebro-basilar aneurysms, because the applied clip is not so short as to close the clival dura safely.

\section{Future Prospect}

The "no-man's land" is no more present in the clival area by the recent development of three kinds of surgical approach. Petroclival meningioma, a benign but the most tough pathology in this area, can be removed by the transpetrosal approach. However, complete tumor resection was risky in the patients with the tumor adhesive to the brain stem, or the tumor encased the basilar system. ${ }^{34}$ Encasement of the carotid artery, extending into the cavernous sinus, reduced the incidence of the total tumor resection. In these patients the tumor eradication was not achieved, radiosurgery will be a best tool to decrease the tumor regrowth. ${ }^{56}$ Limitation of the radiation dose in the tumor close to the brain stem, however, a single problem to be solved in the future. Epidural part of the clival chordoma has been cleared by the transoral approach and subdural part by the transpetrosal approach. The complete tumor resection, however, was not always achieved because the tumor infiltrate widely in the basal skull. Low sensitivity to the radiation therapy was a problem to the recurrent tumors. Biological tumor markers influential to the tumor recurrence, such as MIB-I (Ki-67) ${ }^{57}$ PCNA, ${ }^{58} \mathrm{AgNORs}^{59}$ and neurotensin ${ }^{61}$ have been investigated whether they are useful for markers of clinical tumor malignancy. In the future they will be an indicator of treatment for benign tumors, as well as for malignant tumors.

Clipping of the vertebro-basilar saccular aneurysms in the "no-man's land" became acceptable by the transpetrosal approach or transcondylar approach with minimal surgical intervention. Preservation of the brain stem perforating arteries was a key point of the surgical outcome. Surgically difficult large aneurysms are in the trial of intravascular treatment. Development of catheter technique became possible of aneurysmal packing. ${ }^{61}$ For fusiform or dissecting aneurysms permanent occlusion of the parent artery can be selected, after the test occlusion. The intravascular treatment for broad neck aneurysms has a technical limitation similar to that of the surgical clipping, but will be possible by the technical improvement in the future.

\section{References}

1. Dandy WE, ed: Intracranial Arterial Aneurysms. Ithica, New York, Comstock, 1944, 2-3, 60-66, 130-132

2. Höök $O$, Norlen G, Gurzman J: Saccular aneurysms of the vertebral-basilar arterial system. A report of 28 cases. Acta Neurol Scand 1963. 39: 271-304

3. Logue V: Posterior fossa aneurysms. Clin Neurosurg 1964, 11: $183-219$

4. Jamieson KG: Aneurysms of the vertebrobasilar system. Surgical intervention in 19 cases. J Neurosurg 1964, 21: 781-797

5. Drake CG: Surgical treatment of the ruptured aneurysms of the basilar artery. Experience with 14 cases. J Neurosurg 1965, 23: $457-473$

6. Castellano F, Ruggiero G: Meningiomas of the posterior fossa. Acta Radiol (Suppl) 1953, 104: 1-157

7. Malis LI: Microsurgical treatment of acoustic neurinomas. In: Handa H, ed, Microneurosurgery, Baltimore, University Park Press, 1973

8. Yasargil GY, Fox JL: The microsurgical approach to acoustic neurinomas. Surg Neurol 1974, 2: 393-398

9. Bonnal J, Louis R. Combalbert A: L'abord temporal transtentoriel de l'angle pontocerebelleux et du clivus. NeuroChirurgie 1964, 10: 3-12

10. Yasargil MG, Mortara RW, Curic M: Meningiomas of basal posterior cranial fossa. Adv Tech Stand Neurosurg 1980, 7: $1-115$

11. Symon L: Surgical approaches to the tentorial hiatus. Adv Tech Stand Neurosurg 1982, 9: 69-112

12. Laws ER $\mathrm{J} r$ : Transphenoidal surgery for tumours of the clivus. Head Neck Surg 1984, 92: 100-101

13. Hardy J: Transphenoidal microsurgery of the normal and pathological pituitary. Clin Neurosurg 1969, 16: 185

14. Kanaval AB: Bullet located between the atlas and the base of the skull: technique for removal through the mouth. Surg Clin 1919, 1: $361-366$

15. Stevenson GC, Stoney RJ, Perkins RK, Adams JE: A transcervical transclival approach to the ventral surface of the brain stem for removal of a clival chordoma. J Neurosurg 1966, 24 : $544-551$

16. Mullan S, Naunton R, Hekmat-Panah J, Vailati G: The use of an anterior approach to centrally placed tumors in the foramen magnum and vertebral column. J Neurosurg 1966, 24: 536-543

17. Pasztor $E$ : Transoral approach for epidural craniocervical processes. Ady Tech Stand Neurosurg 1985, 12: 126-164

18. Crockard HA: Anterior approaches to lesions of the upper cervical spine. Clin Neurosurg 1988, 34: 389- $\$ 16$

19. Sano K, Jinbo M, Saito I: Vertcbro-basilar aneurysms, with special reference to the transpharyngeal approach to basilar artery ancurysm. No To Shinkei (Brain and Nerve) 1966, 18: 1197-1203 (in Japanese)

20. Fox JL: Oblitaration of midline vertebral artery aneurysm via basilar craniectomy. J Neurosurg 1967, 26: 406-412

21. Drake CG: The treatment of aneurysms of the posterior circu- 
lation. Clin Neurosurg 1978, 26: 96-144

22. Fisch U: Infratemporal fossa approach to tumors of the temporal bone and base of the skull. J Laryngol Otol 1978, 92: 949-967

23. Glasscock ME III, Miller GW. Drake FD: Surgery of the skull base. Laryngoscope 1978, 88: 905-923

24. Morrison AW, King TT: Experiences with a translabyrinthinetranstentorial approach to the cerebellopontine angle. Technical note. J Neurosurg 1973, 38: 382-390

25. King TT: Combined translabyrinthine-transtentorial approach to acoustic nerve tumors. Proc R Soc Med 1970, 63: 780-782

26. House WF: Surgery of acoustic tumors. Otolaryngol Clin North Am 1973, 6: 245-266

27. Bochenek Z, Kukwa A: An extended approach through the middle cranial fossa to the internal auditory meatus and the cerebellopontine angle. Acta Otolaryngol 1975, 80: 410-414

28. Kanzaki J, Kawase T, Sano H, Shiobara R, Toya S: A modified extended middle cranial fossa approach for acoustic tumors. Arch Otorhinolaryngol 1977, 212: 119-121

29. Hakuba A: Total removal of cerebellopontine angle tumors with a combined transpetrosal-transtentorial approach. No Shinkei Geka 1978, 6: 347-354 (in Japanese)

30. Shiobara R, Ohira T, Kanzaki J, Toya S: A modified extended middle cranial fossa approach for acoustic nerve tumors. J Neurosurg 1989, 68: 358-365

31. Hakuba $A$, Nishimura $S$, Tanaka $K$, Kishi $H$, Nakamura $T$ : Clivus meningioma: six cases of total removal. Neurol Med Chir 1977, 17: 63-77 (in Japanese)

32. Kawase T, Toya S, Shiobara R, Mine S: Transpetrosal approach for aneurysms of the lower basilar artery. $J$ Neurosurg 1985, 63: $857-867$

33. Kawase T, Shiobara R, Toya S: Anterior transpetrosal-transtentorial approach for sphenopetro-clival meningiomas: surgical method and results in 10 patients. Neurosurgery 1991, 2: 869-876

34. Kawase T, Shiobara R, Toya S: Middle fossa transpetrosaltranstentorial approaches for petroclival meningiomas: selective pyramid resection and radicality. Acta Neurochir 1994. 129: $113-120$

35. Al-mefty O, Fox JL, Smith RR: Petrosal approach for petroclival meningiomas. Neurosurgery 1988, 22: 510-517

36. Samii $\mathbf{M}$, Ammirati $M$ : The combined supra-infratentorial presigmoid avenue to the petroclival region. Surgical technique and clinical applications. Acta Neurochir 1988, 95: 6-12

37. Samii M, Ammirati M, Mahran A, Bini W, Sepehrnia A: Surgery of petroclival meningiomas: report of 24 cases. Neurosurgery 1989, 24: 12-17

38. Sen CN, Sekhar LN: The subtemporal and preauricular infratemporal approach to intradural structures ventral to the brain stem. J Neurosurg 1990, 73: 345-354

39. Heros RC: Lateral suboccipital approach for vertebral and vertebrobasilar artery lesions. J Neurosurg 1986, 64: 559-562

40. Perneczky A: The posterolateral approach to the foramen magnum. In: Samii M, ed: Surgery in and around the Brain Stem and the Third Ventricle, Berlin, Springer-Verlag, 1986, 460-466

41. George B, Dematons C, Cophignon J: Lateral approach to the anterior portion of the foramen magnum. Surg Neurol 1988, 29: 484-490

42. Bertalanffy $H$, Seeger $W$ : The dorsolateral, suboccipital, transcondylar approach to the lower clivus and anterior portion of the craniocervical junction. Neurosurgery 1991, 29: 815-821

43. Kawase T, Bertalanffy H, Otani M, Shiobara R, Toya S: Surgical approaches for vertebrobasilar trunk aneurysms located in the midline. Acta Neurochir 1995 (in press)

44. Sen CN, Sekhar LN: An extreme lateral approach to intradural lesions of the cervical spine and foramen magnum. Neurosurgery 1990, 27: 197-204

45. Saito I, Takahashi H, Usui M, Sasaki T, Sano K: Clipping of vertebro-basilar aneurysms by the transoral transclival approach. Neurol Med Chir 1980, 20: 753-758 (in Japanese)

46. Hashi K. Hakuba A. Ikuno $\mathrm{H}$ : A midline vertebral artery aneurysm operated via transoral transclival approach. No Shinkei Geka 1976, 4: 183-189 (in Japanese)

47. Hayakawa T, Yamada K, Yoshimine T: Transoral transclival approach. No Shinkei Geka 1989, 17: 609-614 (in Japanese)

48. Yamaura A, Makino H, Isobe $K$. Takashima T. Nakamura T, Takemiya S: Repair of cerebrospinal fluid fistula following transoral transclival approach to a basilar aneurysm. Technical note. J Neurosurg 1979, 50: 834-836

49. Alonso WA, Black P, Connor GH: Transoral transpalatal approach for resection of clival chordoma. Laryngoscope 1971, 81: $1626-1631$

50. Kennedy DW, Papel ID, Holliday M: Transpalatal approach to the skull base. Ear Nose Throat J 1986, 65: 125-133

51. Crockard HA, Sen CN: The transoral approach for the management of intradural lesions at the craniovertebral junction: review of 7 cases. Neurosurgery 1991, 28: 88-98

52. Uttley D, Moore A, Archer DJ: Surgical management of midline skull-base tumors. J Neurosurg 1989, 71: 705-710

53. James DR. Crockard HA: Surgical access to the base of the skull and upper cervical cord by an extended maxillotomy. Neurosurgery 1991, 29: $411-416$

54. Janecka IP, Sen CN, Sekhar LN, Arriga M: Facial translocation: a new approach to the cranial base. Otolaryng Head Neck Surg 1990, 103: $413-419$

55. Kawase T: Skull base approaches for clival tumors. No Shinkei Geka 1990, 18: 121-128 (in Japanese)

56. Kondziolka D, Lunsford LD, Coffey RJ, Flickinger JC: Stereotactic radiosurgery of meningiomas. J Neurosurg 1991, 74: $552-559$

57. Onda K, Davis RL, Shibuya M, Wilson CB, Hoshino T: Correlation between the bromodeoxyuridine labeling index and MIB-1 and Ki-67 proliferating cell indices in cerebral gliomas. Cancer 1994, 74: 1921-1926

58. Dora WH, Hakim F. Biller BM. De La Monte S, Zervas NT, Klibanski A, Hedley-White T: Significance of proliferating cell nuclear antigen index in predicting pituitary adenoma recurrence. J Neurosurg 1993, 78: 753-761

59. Orita T, Kajiwara K, Nishizaki T, Ikeda N, Kamiryo T, Aoki H: Nucleolar organizer regions in meningioma. Neurosurgery 1990 , 26: $43-46$

60. Przedborski S. Levivier M, Cadet JL: Neurotensin receptors in human meningiomas. Ann Neurol 1991, 30: 650-654

61. Guglielmi G, Vinuela F, Sepetka I, Macellari V: Electrothrombosis of saccular aneurysms via endovascular approach. Part 1: Electrochemical basis, technique, and experimental results. J Neurosurg 1991, 75: 1-7 